\title{
CARACTERIZAÇÃO E ÍNDICE DA QUALIDADE DO SANEAMENTOAMBIENTALA PARTIR DE MODELOS GEOTECNOLÓGICOS E ANÁLISE MULTIVARIADA
}

\author{
Paulo Eduardo Alves Borges da Silva
}

\section{Resumo}

O fenômeno da expansão das cidades inerte a um planejamento reestruturador pode representar uma ameaça à qualidade de vida nos centros urbanos, principalmente nas áreas periféricas,ocupadas majoritariamente por parcelas da população socioeconomicamente menos favorecidas. São recorrentes os desastres ambientais e o incremento da demanda de serviços. Nesse ínterim, destaque para a provisão do saneamento básico: desde a existência de sanitários nos domicílios até a instalação da distribuição de água, tratamento de esgoto, bem como a coleta de lixo. Destarte, a temática da qualidade do saneamento ambiental denota uma associação entre a disponibilidade de infraestrutura e seus impactos correlacionados ao meio ambiente e quem o habita. Este trabalho buscou caracterizar a condição da distribuição espacial da qualidade do saneamento ambiental em uma grande metrópole brasileira - Belo Horizonte - utilizando dados em nível de setores censitários por razão de domicílios, possibilitando uma análise multiescalar. Para tal, técnicas de sensoriamento remoto e geoprocessamento mostraram-se adequadas: aspectos domiciliares geocodificados explicitaram a espacialização dos serviços e infraestrutura e, a partir das imagens de satélite e procedimentos de classificação, pôde-se mensurar a distribuição das áreas verdes e vazios urbanos, presença de corpos hídricos e zonas potenciais de alagamento. Por fim, uma análise estatística multivariada (discriminante) permitiu a elaboração de um indicador sintético do grau de saneamento ambiental por setores censitários. Acredita-se que os resultados deste trabalho possam contribuir para a difusão dessas técnicas e a elaboração de políticas públicas sustentáveis capazes de avaliar e prever as condições da população residente urbana, no que diz respeito ao saneamento ambiental.

Palavras chave:Saneamento; Qualidade; Índice; Modelos; Análise Multivariada.

\footnotetext{
- Universidade Federal de Minas Gerais. Instituto de Geociências.(Geógrafo. Mestrando em Análise e Modelagem de Sistemas Ambientais).pauloeduardoborges@gmail.com 


\begin{abstract}
The expansion of cities without a restructurer plan represents a threat to quality of life in urbancenters, principally in the peripheral areas. These places are mainly occupied by groups of peoplesocioeconomically disadvantaged and where are frequent environmental disasters and increasing demand for services. Emphasis on the provision of basic sanitation: the existence of toilets in private homes, installation of water distribution, sewage treatment and garbage collection. The issue of environmental sanitation quality is an association between the availability of infrastructure, impactsrelated to the environment and who inhabits the space. This study aimed to characterize the condition of the spatial distribution of environmental sanitation in a large Brazilian city - Belo Horizonte - using data at the level of census sectors by reason of households, enabling a multiscale analysis. For this, remote sensing and GIS techniques are presented adequate: geocoded household aspects explained the spatial distribution of services and infrastructure. From the satellite images and classification procedures, was estimated the distribution of green areas and urban voids, the presence of water bodies and areas of potential flooding. Finally, a multivariate statistical analysis (discriminant) allowed the preparation of a synthetic indicator: the degree of environmental sanitation quality by census sectors at different probabilistic levels. It is believed that the results of this article can contribute to the development of sustainable public policies capable of assessing and predicting the conditions of the urban resident population, with regard to environmental sanitation.
\end{abstract}

Keywords:Sanitation, Quality, Index, Models; Multivariate Analysis.

\title{
1 -INTRODUÇÃO
}

Ao mesmo tempo em que se trata de uma ação de saúde pública e proteção ambiental,o Saneamento traz consigo uma multiplicidade de funções, pois, é um bem de consumo coletivo, um serviço fundamental ao homem e, consequentemente, um direito do cidadão e dever do Estado. Portanto, sua atuação se enquadra nas políticas públicas e sociais e a promoção deve ser fruto de ações conjuntas.

O desafio decorrente da urbanização consiste na harmonização dos objetivos dodesenvolvimento da saúde e do ambiente, assim como os da equidade social para os que necessitam da formulação de políticas efetivas de desenvolvimento urbano. A repercussão na saúde devido às consequências do crescimento urbano desordenado, especificamente em relação à falta de saneamento básico, ainda pode ser identificada através dos índices de 
mortalidade por doenças infecto-contagiosas, principalmente nas menores faixas etárias (OKANO et al, 2009).

Segundo OPAS (2007), saneamento básico é o conjunto de ações que se executam noâmbito do ecossistema humano para o melhoramento dos serviços de abastecimento de água, coleta de esgoto, o manejo dos resíduos sólidos, a higiene domiciliar e o uso industrial da água, em um contexto político, legal e institucional no qual participam diversos atores do âmbito nacional, regional e local. Vale ressaltar que este conjunto de ações mantém uma interrelação permanente entre a gestão do saneamento básico e a saúde pública.

Desse modo, este trabalho tem como objetivo principal avaliar a situação dosaneamento num contexto abrangente, onde variáveis ambientais e econômica são agrupadasaos fatores já conhecidos de infraestrutura de saneamento básico: água, esgoto e lixo. Assim,a proposta é caracterizar a qualidade do saneamento ambiental, através da criação de um índice sintético, obtido por meio de técnicas de análise estatística multivariada. A obtenção deresultados das variáveis ambientais físicas - áreas verdes, corpos hídricos, áreas potenciais dealagamento e vazios urbanos - se dá através de procedimentos de Sensoriamento Remoto eGeoprocessamento e a combinação final das variáveis tem como fator preponderante a Renda,condição relativa de indicador de boa infraestrutura.

Além disso, o esforço realizado nesta pesquisa busca ceder informações para um debate não só acadêmico, como também no eixo da gestão participativa; selecionar variáveis que correlacionem à infraestrutura urbana e meio ambiente disponibilizadas pelo Censo everificar o poder de explicação das mesmas num modelo integrado; obter, a partir de técnicas de sensoriamento remoto e recorte espacial, dados que agreguem valor e complementem a análise do saneamento; elaborar um banco de dados geocodificado das variáveis; difundir ametodologia; gerar um indicador de tipologia para Belo Horizonte e confeccionar um mapasíntesedas unidades em questão. Os procedimentos adotados compreendem etapas onde as atividades de leitura e a montagem / manuseio de dados foram imprescindíveis.

\section{2 - MEIO AMBIENTE URBANO E SANEAMENTO}

Boa parte da sociedade refere-se ao meio ambiente trazendo a efígie de áreas naturais não-antropizadas, por vezes associadas a uma paisagem rural, ou um local onde há a existência de ampla cobertura vegetal e riqueza hidrológica. Porém, a área urbanizada de ummunicípio, ou seja, o palco de significativas alterações humanas no que um dia já foi territóriopassível exclusivamente das dinâmicas da Natureza, pode ser denominado como um meio ambiente 
urbano. Nele devem ser encontradas todas as preocupações ambientais acrescidas do fator humano e sua ocupação: habitação, arruamentos, meios de transporte, obras, dentreoutros. Entre estas transformações, incluem-se também os meios produtivos, que vão desde aformação educacional até as empresas e indústrias.

Diante das necessidades humanas ao longo de toda a história, muitos problemas surgiram relacionados ao ambiente com um todo. Desponta na sociedade inquietações vinculadas à sua conservação e qualidade, o que trouxe uma importância ainda maior aos estudos neste âmbito, para que se alcance uma melhor qualidade de vida nas aglomerações.

Hoje, as cidades podem ser consideradas como ecossistemas, abertos e de grandes proporções, capazes de atingir longas distâncias. Além dessa questão de influência multiescalar, pode-se dizer que os estudos referentes ao meio ambiente urbano tornamsecomplexos na medida em que devem ser considerados não só toda uma gama de recursos naturais utilizados, como também as decorrências (positivas ou não) advindas das transformações de um meio que um dia já foi "intacto". Na ocorrência deste estudo, voltamseas atenções para as condições ambientais no meio urbano e suas implicações para a população, no cerne do saneamento básico e seus aspectos ambientais relacionados, os quaisafetarão na qualidade de vida.

Segundo a Lei federal n ${ }^{\circ} 11.445$, de 5 de Janeiro de $2007^{1}$, o saneamento básico pode ser entendido como o "conjunto de serviços, infra-estruturas e instalações operacionais de: abastecimento de água potável, esgotamento sanitário, limpeza urbana, manejo de resíduos sólidos e drenagem e manejo das águas pluviais." Mas seja qual for a definição utilizada, é adequado dizer que o saneamento básico está intimamente relacionado às condições de saúdeda população e mais do que simplesmente garantir acesso aos serviços, instalações ou estruturas que citam a lei, envolve, também, medidas de educação da população em geral e abusca de uma conservação dos recursos ambientais.

Para conseguir agregar condições vitais adequadas à população, é preciso atualmente direcionar a análise urbanística para propostas de ocupação nos municípios, de modo que seexplorem os potenciais locais, corrijam erros organizativos e eliminem pontos críticos de riscos - relacionado à moradia - e de insalubridade (BONDUKI, 2003). Em nosso país, garantir um ambiente saudável e que preserve os patrimônios naturais é uma tarefa com custos

\footnotetext{
${ }^{1}$ BRASIL, Lei $\mathrm{n}^{\mathrm{o}}$ 11.445, de 5 de Janeiro de 2007. Estabelece diretrizes nacionais para o saneamento básico;altera as Leis nos 6.766, de 19 de dezembro de 1979, 8.036, de 11 de maio de 1990, 8.666, de 21 de junho de 1993, 8.987, de 13 de fevereiro de 1995; revoga a Lei no 6.528, de 11 de maio de 1978; e dá outras providências.
} 
altíssimos, fato que dificulta ainda mais a manutenção das condições salutares às instalações da população. Segundo o Ministério das Cidades², “(...) são necessários investimentos de cerca de $\mathrm{R} \$ 20$ bilhões anuais nas próximas duas décadas para garantir moradia digna e saneamento básico para atender as famílias com renda de zero a cinco salários mínimos.”

Carências graves são também observadas na área de drenagem urbana, submetendo diversos municípios a periódicas enchentes e inundações, além de problemas de saúde públicaresultantes do escoamento deficiente das águas de chuva (BARROS, 1995). O escoamento pluvial se dá através da instalação de bueiros e bocas-de-lobo que funcionam com um input das águas e direcionam o fluxo coletado, na maioria das vezes, para os cursos d'água através de canalizações. Uma preocupação em nosso país e que é digna de nota, são os acúmulos deresíduos nas vias, o que provocaria uma poluição indireta nos rios. Em função disso, já existem amplos estudos e propostas de melhor tratamento e destinação dessas águas. A faltade planejamento e estrutura nesse sistema pode acarretar inúmeras dificuldades nas aglomerações urbanas, fato frequentemente observado em muitas localidades brasileiras.

O saneamento nas cidades não interfere apenas na vida e atividades de seus habitantes, pois sua capacidade de provisão e impactos podem alterar e influenciar o ambiente em escalalocal e global. Ou seja, já que as cidades estão inseridas em um maior contexto, pode-se dizerque problemas desse meio resultam da soma de vários impactos em diferentes segmentos (LIMA \& AMORIM, 2002), seja o seu abastecimento, infraestrutura ou suporte.

Considera-se que o ambiente é formado pelo sistema natural - meio físico e biológico e pelo sistema antrópico - constituído pelo homem e suas atividades. Ao ocupá-lo e utilizálopara a construção das cidades e/ou expansão, a sociedade altera o meio natural muitas vezes sem planejar os espaços que estão sendo alterados (LIMA, 2007). Isso pode refletir na própriacapacidade e nível de sobrevivência da população, que, além de desfrutar dos elementos naturais do espaço, deve ter meios que contribuam para a sua conservação, buscando aproximar-se daquilo que chamamos de sustentabilidade.

O saneamento ambiental urbano pode ser considerado como um aspecto importante de equilíbrio entre a ocupação das cidades e os elementos da paisagem não-modificada, somadoao acesso às infraestruturas básicas dos equipamentos habitacionais que privilegiem condições salubres e de conforto. Estes serviços devem ser bem delineados e implementadosatravés de um planejamento.

\footnotetext{
2 BRASIL, Ministério das Cidades. Cadernos Ministério das Cidades Saneamento ambiental. Volume 5: Saneamento ambiental. Governo Federal, 2005, pág. 49. 
E, muito embora existam amplas discussões sobre a problemática ambiental nos centros urbanos na atualidade, o embasamento teórico e metodológico ainda está em processode construção. Ao tratar das perspectivas de análise da questão ambiental no lócus urbano, chama-se a atenção para o fato de que “(...) se o apoio teórico sobre a relação sociedadenaturezaem sua forma atual ainda está por se consolidar, o assunto torna-se ainda maisrarefeito quando se trata da combinação cidade-ambiente" (CIDADE, 1996).

Compreender estas e outras abordagens faz com que as percepções a respeito do meio ambiente urbano incluam uma visão geral da relação natureza-homem-controle. A sociedadeutiliza a natureza como recurso, apropriando-se e transformando o espaço, ao mesmo tempoem que é preciso criar condições de manutenção do meio (gestão) para que essa ocupação ouuso possa ser menos impactante possível.

\section{3 - ÍNDICE DA QUALIDADE DO SANEAMENTO AMBIENTAL - IDQS}

Outra questão fundamental na avaliação de parâmetros que privilegiem a qualidade do saneamento ambiental é a construção de índices confiáveis que possam representar, de formasintética, um conjunto de indicadores diversificados e orientar, de forma objetiva, as políticaspúblicas. No que diz respeito a estes indicadores, grande esforço vem sendo feito desde oinício da década de 60 e destacadamente na década de 70 - para a incorporação da variável ambiental no movimento dos indicadores sociais. A primeira tentativa de estabelecimento deindicadores ambientais urbanos se deu na década de 70 através da OCDE Organización deCooperación y Desarrollo Económico, não obtendo, contudo, muitos resultados (BORJA, 2003).

Os esforços atuais têm se concentrado na avaliação da qualidade de vida em sua dimensão social e ambiental. No que se refere aos objetivos de um sistema de indicadores, Will e Brigg (1995) acreditam que sejam um meio de prover as políticas com informações, dedemonstrar seu desempenho ao longo do tempo e de realizar previsões, podendo ser utilizadospara a promoção de políticas específicas e monitoração de variações espaciais e temporais.

A questão da avaliação do saneamento básico das cidades recai na questão da definição de indicadores ambientais. Para Januzzi apud Morett (2002) tais indicadores "dizemrespeito à disponibilidade de recursos naturais, à forma de uso dos mesmos e aos resíduos gerados no seu consumo". Para Luengo (1998), um dos problemas fundamentais para a determinação da qualidade ambiental é a definição de indicadores confiáveis referidos aos diferentes aspectos a 
serem considerados, que desse modo incidem "três grandes aspectos decaráter geral que atuam como referencia para a avaliação da qualidade ambiental: físiconaturais,urbanoarquitetônicos e sócio-culturais" (LUENGO,1998).

Destarte, os indicadores de qualidade ambiental urbana devem avaliar a capacidade que envolve disponibilidade e acesso - da estrutura, da infra-estrutura, dos equipamentos e serviços urbanos de uma determinada localidade, na satisfação das necessidades da populaçãoe no aumento de seu bem-estar.

Neste sentido, dados demográficos disponíveis em nível de setores censitários contribuem significativamente para uma análise robusta em relação ao todo (município). Nocaso brasileiro, o censo demográfico coleta informações que estão relacionadas à condição deinfraestrutura e relacionadas ao uso e destino de recursos naturais: distribuição de água, coleta 7 de lixo, esgoto, dentre outros (IBGE,2000). No entanto, outras variáveis que conduziriam auma análise ambiental-urbana conjunta levando em conta fatores como a distribuição da vegetação, de disponibilidade de recursos hídricos não são registradas. Assim, cria-se a necessidade de associação de metodologias diferenciadas e interdisciplinares.

Classificar e/ou criar tipologias dos setores censitários urbanos conforme sua qualidade de saneamento incluiria a reunião de múltiplas variáveis distribuídas por estas unidades e a aplicação de métodos estatísticos que verificassem tanto o poder explicativo dasmesmas, quanto o desenvolvimento de um modelo de classificação múltiplo para as áreas deinteresse.

Um problema comum em muitas ocorrências de análise de dados é quando há dois ou mais grupos de objetos formando amostras de duas ou mais populações, para as quais um número de características é medido e deseja-se classificar objetos similares desconhecidos, baseando-se no mesmo conjunto de atribuições. Uma técnica estatística a qual tem sido aplicada largamente para esse propósito é a análise de discriminante (FERGUSON, 1994).

A combinação destes objetos gera um resultado probabilístico de pertencimento (probabilities of membership) de cada variável ao número de classes previamente estabelecidas. A elaboração de um índice a partir destes resultados advém da análise combinatória destes grupos diante de um único fator de todo o grupo, ou seja, uma variável dependente. O resultado é um referencial numérico - tipologia - levando em consideração todos os dados do bloco, obtendo-se, portanto o indicador (FERREIRA, 2007). Nestetrabalho, a proposta leva em consideração não só as reflexões que remontam à composição deste grupo de variáveis, mas também a capacidade do resultado de categorização alcançada pelo Índice. 


\section{4 - METODOLOGIA E RESULTADOS}

Para o desenvolvimento do trabalho, a metodologia apoia-se nos pressupostos de obtenção das informações sobre saneamento ambiental urbano para a área em interesse, aliados a uma revisão bibliográfica que facilite a compreensão da configuração urbanoambientallocal. Além disso, há um esforço em utilizar as amplas ferramentas geotecnológicas existentes, com vistas a trabalhar os dados espacialmente. As etapas podem ser descritas da seguinte maneira e estão intrínsecas aos objetivos específicos.

\subsection{Fundamentação Teórica}

Discussão sobre o conceito de saneamento, sua relação com o meio ambiente urbano e dimensão da qualidade ambiental; descrição da escolha do método estatístico a ser utilizado na geração do índice.

\subsection{Definição das variáveis do Censo 2000}

Foram selecionadas variáveis de infraestrutura que demonstram características positivas $^{3}$ de análise, de modo que haja uma correlação qualitativa entre a informaçãopretendida. Para se chegar ao produto final - Índice - os valores precisaram ser discretizados, pois, os disponibilizados pelo IBGE são absolutos por setores censitários. Decidiu-se trabalhar, portanto, com o conceito de Razão por Domicílios. E como já mencionado, a variável Renda - que remete à ideia de boa infraestrutura - também foi selecionada, de modoa potencializar o indicador, revelando a aproximação desse com a socioeconomia.

\subsection{Definição das variáveis adquiridas com técnicas de Sensoriamento Remoto}

Os fatores ambientais físicos incorporados no modelo foram extraídos de análise de processamento digital de imagens CBERS, datadas de 06 de Setembro de $2008^{4}$ (Figura 1) e Classificação no software ENVI 4.5. A câmera de alta resolução (CCD), tem 5 bandas e

\footnotetext{
${ }^{3}$ Exemplo: domicílios particulares permanentes COM coleta de lixo.

4 Ainda que as variáveis agregadas do Censo sejam do ano de 2000, a escolha de cenas de satélite recentes (2008) deve-se ao fato da disponibilidade de material de qualidade, com satisfatória correção radiométrica, além da busca por uma caracterização dos aspectos do meio físico atualizada.
} 
fornece imagens de uma faixa de $113 \mathrm{Km}$ de largura. Sua resolução temporal é de 26 dias e,por apresentar boa resolução espacial - 20 metros - em quatro bandas espectrais, mais uma pancromática, tem uso variado, principalmente naqueles de observação de ocorrências ou cujonível de detalhe seja indispensável. Como destaque e de relevância para este trabalho, uma das principais aplicações potenciais da câmera CCD para estudos municipais é a identificaçãode áreas verdes e distinção de alvos urbanos (INPE, 2007).

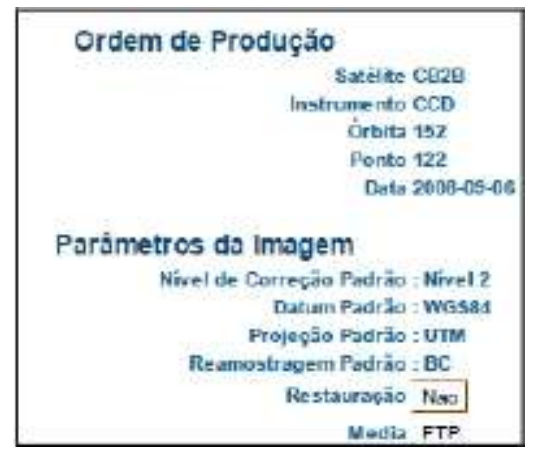

Figura 1: Parâmetros da Imagem selecionada. Fonte: INPE, catálogo CBERS.

Foram escolhidas as bandas 2, 3 e 4, agrupadas numa composição colorida (R3G4B2) e geração de imagem sintética. Trata-se de uma composição de bandas que realça o uso dosolo e, neste caso temos uma composição infravermelho falsa-cor - banda 4 - onde a vegetação aparece em verde, o solo exposto em tons mais claros, mancha urbana em tons avermelhados, água e áreas úmidas em tons azuis (Figura 2).

Primeiramente foi feita a correção geométrica da mesma, utilizando a malha de setores censitários urbanos de Belo Horizonte ${ }^{5}$. Em seguida, operações triviais de alteração nocontraste (ajuste) foram utilizadas sistematicamente e de forma padrão: distribuição linear dohistograma em $2 \%$ em todas as etapas que envolveram a participação de um intérprete. Esserealce proporcionou uma melhor identificação dos objetos, apesar de que foram observadosalguns ruídos nas bordas dos alvos. Dessa maneira, a filtragem Gaussiana pôde solucionar parte dessas impurezas de detalhe.

\footnotetext{
${ }^{5} \mathrm{O}$ georreferenciamento da imagem sintética por meio das feições obteve bons laores de erro RMS, pois, algunssetores censitários expressam a delimitação exata de parques ou grandes equipamentos urbanos, o que facilita avisualização e demarcação. Neste procedimento foram determinados 30 pontos de controle.
} 


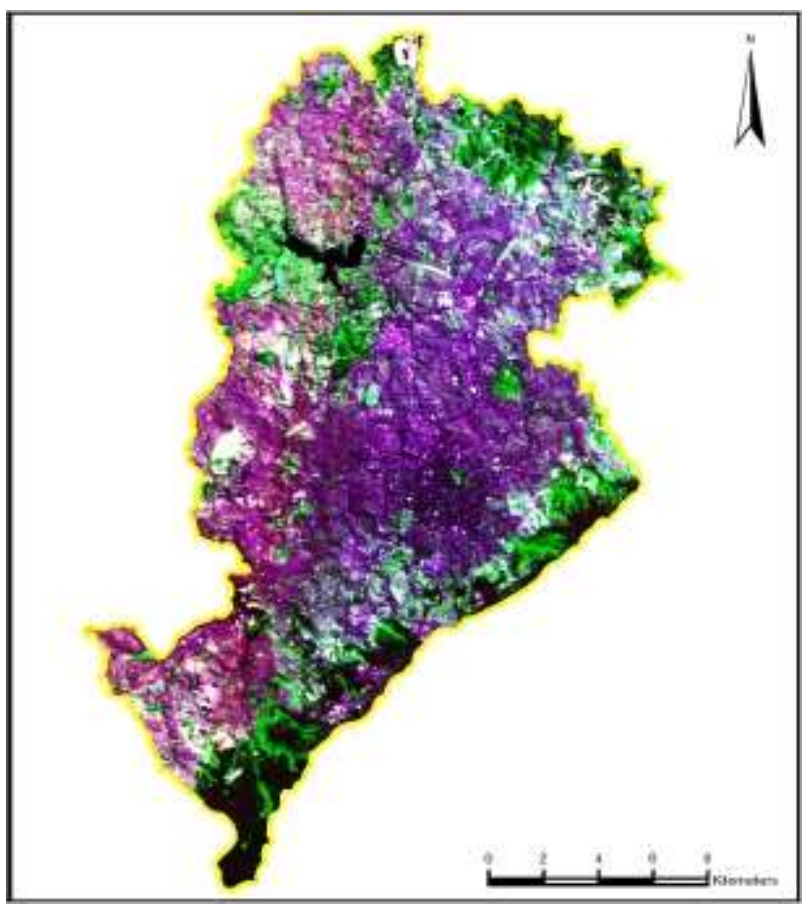

Figura 2: Composição colorida CBERS RGB342 realizada

Com as devidas correções e geração de uma imagem sintética de boa qualidade, osprocedimentos de classificação supervisionada foram adotados no software ENVI. Nesta operação o usuário seleciona amostras para cada uma das classes que se desejaidentificar na imagem. As classes podem ser descritas por uma função densidade deprobabilidade e, portanto, descritas por seus parâmetros estatísticos. Estes parâmetros são estimados através do conjunto de amostras de treinamento, previamente selecionados. A função densidade de probabilidade será, então, usada como um critério de decisão sobre a que classe um pixel pertence. Para a temática deste trabalho, o objetivo era identificar a áreas verdes (todo e 
qualquer pixel relacionado às árvores e/ou cobertura vegetal; os vazios urbanos (solo exposto e lotes vagos); corpos hídricos; áreas potenciais de alagamento.

Para as três primeiras classes acima descritas, o método classificador utilizado foi o algoritmo de máxima verossimilhança (MAXVER) e foi adotado um universo de 35 amostras para determinação de cada categoria, de forma que alguns resultados cruzados - corpos d'água e áreas verdes - foram filtrados. O produto final obteve bons parâmetros, se comparado tanto com a imagem sintética quanto. Para a elaboração das amostras e conferência, foram utilizadas algumas bases cartográficasmunicipais: (Áreas Verdes - Fundação de Parques de Belo Horizonte e Espaços

Vazios - Lotes vagos do Cadastro Técnico Municipal / IPTU - Prodabel).

Para as áreas potenciais de alagamento, a metodologia utilizada foi a criação de um mapa de declividade para todo o município, a partir de curvas de nível interpoladas de 5 metros. Em seguida, realizou-se a extração das áreas onde a declividade não ultrapassa 4 graus e há contato ou proximidade de 50 metros(buffer) com cursos d'água e/ou galerias de drenagem urbana. O resultado trouxe manchas isoladas, frequentes em áreas mais aplainadas e, típicas de eventos de

enchentes conhecidos, como a região nordeste da capital.

Finalizado o processo de Classificação de Imagens, foi preciso transformar osdados dos rasters em tabelas numéricas, mantendo a classificação e espacialização adquirida para, posteriormente, trazê-las ao formato vetor (Figura 3). O formato poligonal possibilitaria calcular em metros quadrados cada ocorrência pontual no território. O procedimento sequente e não-trivial foi o cruzamento destas feições com a base de setores censitários, de modo que se obtivesse a área de ocorrência das classes em cada unidade de análise sociodemográfica. Para isso, a ferramenta de interseção e cálculo de geometria do software ArcGiS 9.2 foi fundamental. 


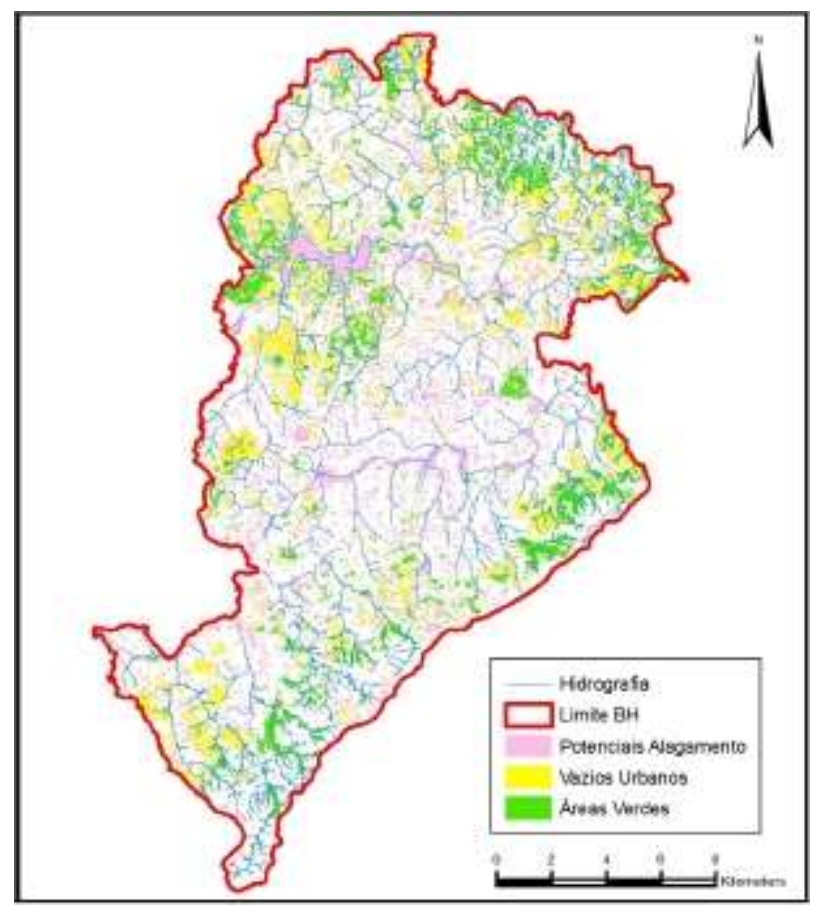

Figura 3: Feições extraídas da classificação MAXVER.

\subsection{Montagem do Banco de Dados e Análise de Discriminante}

Finalizado o tratamento dos dados do Censo e daqueles adquiridos pelosprocedimentos de Sensoriamento Remoto e Geoprocessamento, foi preciso agrupá-los (Tabela1) num banco, de forma bem estruturada e correlacionada ao código do setor censitário. Todos os resultados das variáveis ${ }^{6}$ foram ponderados pelo número absoluto de domicílios em cada célula ou setor (Tabela 2).

\footnotetext{
${ }^{6}$ Exceto a variável renda.
} 
Tabela 1: Síntese das Variáveis utilizadas no modelo de análise multivariada

\begin{tabular}{|c|c|c|}
\hline VARIÁVEL. & DESCRIÇAOO & VALORES \\
\hline $\begin{array}{l}\text { DOM } \\
\text { V01 }\end{array}$ & 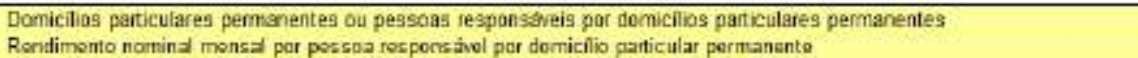 & persumo \\
\hline vo2 & Domicilias particulares permanentes cam abastecimento de ägua da rede geral & \multirow{11}{*}{$\begin{array}{l}R \\
A \\
Z \\
A \\
D \\
0\end{array}$} \\
\hline vo3 & Damiclios perticulares permanentes com abastecimento de apua da rade geral e canalzaçäo em pelo menas um cómodo & \\
\hline V04 & Domicilios particulares pemanentes com banheiro ou santario & \\
\hline vos & Domicilias particulares permarentes cam banheiro ou sanitario e esgatamento santäno via rede geral de esgoto ou plwial & \\
\hline Vos & Darmiclios particulares parmenentes cam banheiro & \\
\hline ve? & Domicibos particulares permenentes com lixo coletado & \\
\hline v08 & Domicilas particularee permenentes com lixo coletado per seniço de impeza & \\
\hline vo9 & Domicilias particulares permanentes cam fixo coletade am caçamba de saviça de limpeza & \\
\hline v10 & Arabs Verdes por Setor Cenaitario am motros quadrados & \\
\hline v11 & Ávea de Vazos Uibenos por Setor Censitanio em metros quadrados & \\
\hline $\mathrm{V} 12$ & Aveas Potenciais de Alogarnenta par Setur Censitátin em metros quadrados. & \\
\hline & $\begin{array}{l}\text { Variáeis do Censa Demagráficu, } 2000 . \\
\text { Variáveis abxidas pelas técnicas Gectacnalógicas, } 2008 .\end{array}$ & \\
\hline
\end{tabular}

Fonte: Censo Demográfico 2000 e definições do autor.

Tabela 2: Amostra do Banco de Dados por Razão de Domicilios nos Setores Censitários

\begin{tabular}{|c|c|c|c|c|c|c|c|c|c|c|c|c|c|}
\hline CODSETOR & DOM & V01 & V02 & V03 & V04 & V05 & V06 & V07 & V08 & V09 & V10 & V11 & V12 \\
\hline 310620005620001 & 174 & 2868.12 & 1.0000 & 1.0000 & 1,0000 & 1,0000 & 1,0000 & 1.0000 & 1,0000 & 0.0000 & 0,0000 & 0,0000 & 0.0000 \\
\hline 310620005620002 & 205 & 4666,80 & 0.9654 & 0,9654 & 1,0000 & 1,0000 & 1,0000 & 1,0000 & 1.0000 & 0.0000 & 0,0000 & 0,0000 & 0.0000 \\
\hline 310620005620003 & 212 & 4707,53 & 1.0000 & 1,0000 & 1,0000 & 1,0000 & 10000 & 1,0000 & 1,0000 & 0.0000 & 0,0000 & 0,0000 & 38,1439 \\
\hline 310620005620004 & 238 & 2995,62 & 10000 & 1,0000 & 1,0000 & 1,0000 & 0,9958 & 10000 & 1,0000 & 0,0000 & 2,0462 & 0,0000 & 51,8622 \\
\hline 310620005620005 & 241 & 3375,94 & 1.0000 & 0.9959 & 1,0000 & 1.0000 & 0,9959 & 1.0000 & 1,0000 & 0.0000 & 4.1303 & 1,1365 & 71,1320 \\
\hline 310620005620006 & 281 & 6234.95 & 1.0000 & 1.0000 & 1,0000 & 1,0000 & 1.0000 & 1.0000 & 1,0000 & 0,0000 & 25,1762 & 0,0000 & 51.5427 \\
\hline 310620005620007 & 317 & 5707,43 & 0,9968 & 0,9968 & 1,0000 & 1,0000 & 1,0000 & 1,0000 & 1,0000 & 0,0000 & 9,5798 & 0,0000 & 11,8240 \\
\hline 310620005620008 & 207 & 3677,97 & 10000 & 1,0000 & 1,0000 & 1,0000 & 1,0000 & 10000 & 1,0000 & 0,0000 & 9,6618 & 0,0000 & 15,7845 \\
\hline 310620005620009 & 316 & 5342,94 & 1,0000 & 1,0000 & 1,0000 & 1,0000 & 1,0000 & 1,0000 & 0,9430 & 0.0570 & 4.1994 & 2.4788 & 61.0848 \\
\hline
\end{tabular}

Fonte: Manipulação de Dados.

Com o Banco de Dados pronto, as técnicas de estatística puderam ser realizadas no software SPSS. Como o objetivo final era a geração de um índice com 5 classes (crítico,baixo, médio-baixo, médio e alto), a Análise de Discriminante com a probabilidade de pertencimento foi trabalhada com a dimensão de 5 unidades (steps), para posteriormente combiná-las à variável Renda e obter uma categorização individual, ou seja, o indicador relativo de cada setor censitário (Tabela 3). Os resultados percentuais do número de setorespor cada categoria pode ser observado na Figura 4 a seguir.

Cadernos do Leste 
Tabela 3: Amostra do Banco de Dados com resultado da Análise de Discriminante

\begin{tabular}{|cccccccc|}
\hline CODSETOR & Renda & Dis1 & Dis1_1 & Dis2_1 & Dis3_1 & Dis4_1 & Dis5_1 \\
310620005620001 & 5 & 4 & 0,03642 & 0,20133 & 0,24574 & 0,26024 & 0,25628 \\
310620005620002 & 5 & 3 & 0,07090 & 0,23567 & 0,25207 & 0,22930 & 0,21206 \\
310620005620003 & 5 & 5 & 0,03320 & 0,19344 & 0,24384 & 0,26418 & 0,26534 \\
310620005620004 & 2 & 4 & 0,12718 & 0,19830 & 0,22508 & 0,22942 & 0,22003 \\
310620005620005 & 5 & 3 & 0,04686 & 0,21343 & 0,24975 & 0,24972 & 0,24024 \\
310620005620006 & 3 & 1 & 0,47866 & 0,26789 & 0,13551 & 0,07100 & 0,04694 \\
310620005620007 & 4 & 5 & 0,03130 & 0,18591 & 0,23786 & 0,26821 & 0,27672 \\
310620005620008 & 3 & 4 & 0,03987 & 0,20509 & 0,24773 & 0,25672 & 0,25058 \\
310620005620009 & 1 & 2 & 0,20854 & 0,25376 & 0,24021 & 0,16288 & 0,13460 \\
\hline
\end{tabular}

Fonte: Manipulação de Dados e análise multivariada.

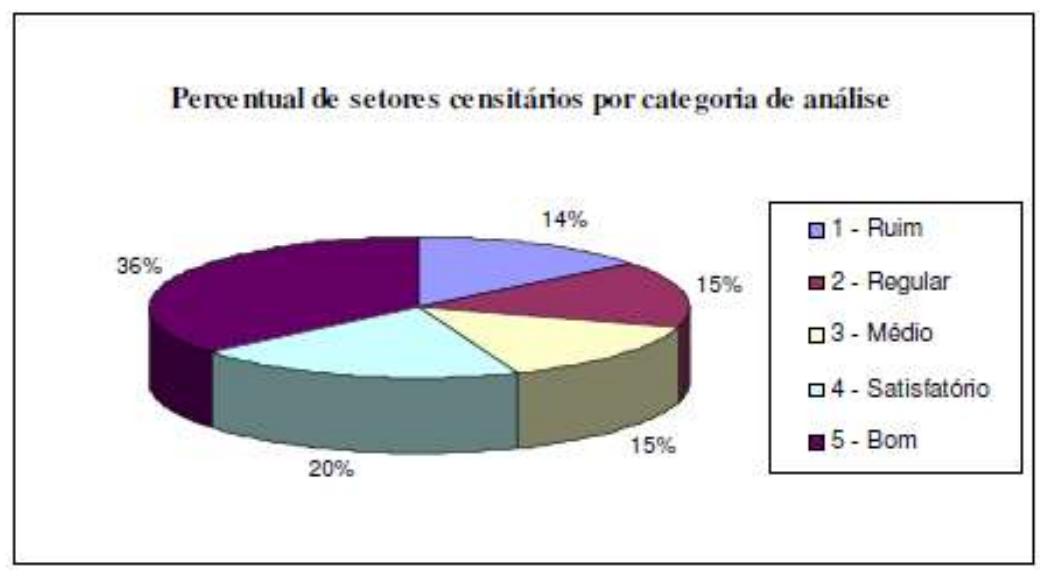

Figura 4: Gráfico da distribuição dos setores censitários por categorias. Fonte: Análise dos dados.

Por fim, restou apenas agregar os resultados tabulados às feições espaciais domunicípio de Belo Horizonte e gerar um mapa-síntese por manchas da categorização implementada. Para efeitos de percepção qualitativa, aderiu-se novos termos às classes, respondendo agora por: ruim, regular, médio, satisfatório e bom (Figura 5). 


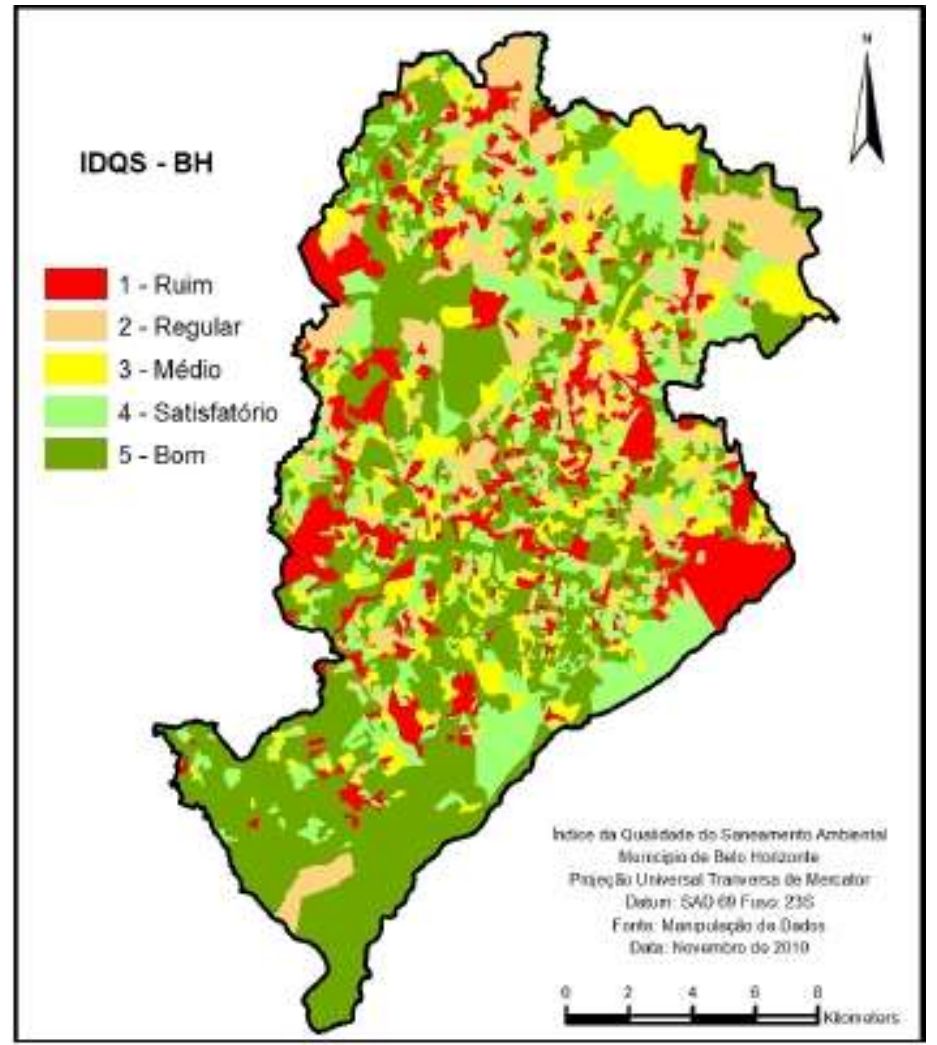

Figura 5: Mapa-Síntese de Distribuição do Índice da Qualidade do Saneamento Ambiental.

\section{5 - Considerações Finais}

As observações feitas a partir da interpretação do mapa-síntese trazem consigo um significado de explicação inerente às variáveis utilizadas na elaboração do índice. Há de se investigar quais hipóteses individuais influenciaram na resposta do indicador e, posteriormente produzir informações da municipalidade como um todo.

Através da análise do mapa, que demonstra a espacialização do IDQS, pode-se perceber que na porção sul do município de Belo Horizonte predomina uma boa condição. Uma das hipóteses para que isso ocorra é a presença de grandes áreas verdes na região, representada principalmente pelo Parque das Mangabeiras na Serra do Curral. Outra possibilidade seria o fato de que tal área possui indicadores elevados de renda e suposta qualidade de vida adequada. Entretanto, todas essas hipóteses não deixam a região sulina isenta da presença de espaços críticos com IDQS abaixo de regular. Tal fato pode ser explicado pela presença de aglomerados suburbanos - os quais têm infraestrutura irregular desaneamento - e áreas pontuais sujeitas a alagamentos. 
Por sua vez, na porção central, índices que vão de ruim a bom podem ser observados.A boa qualidade de alguns espaços pode ser explicada pela presença de áreas verdes centrais (Parque Municipal, por exemplo), assim como pela maior preocupação com uma das áreas mais valorizadas no contexto imobiliário. Já as porções regulares e ruins aparecem devido à falta de conforto, poluição, o excesso de espaços urbanizados, dentre outros motivos.

O norte de Belo Horizonte apresenta áreas com IDQS de satisfatório a bom que pode ser explicado pela presença de áreas verdes como a região da Pampulha, o Parque Ecológico eFundação Zoo-Botânica. Além disso, a presença de áreas nobres e elevada renda, com predominância de casas, pode indicar uma boa qualidade de vida desses moradores e suporte de saneamento básico considerado bom. No entanto, assim como as demais regiões, ela não está isenta de áreas com Indicador de regular a ruim, fato que pode estar relacionado à presença de populações situadas em locais com saneamento precário e também sujeitas a alagamentos.

A presença de espaços críticos na porção noroeste é considerável, pois existem áreas sujeitas a alagamento e existe boa parcela da população residente com renda média a baixa, ou seja, lócus menos favorecidos. Porém existem também porções com bom IDQS e podemser justificadas pela influência no modelo adotado das áreas verdes e espaços vazios (que representam uma menor pressão sobre os recursos físicos e estruturais).

A região oeste tem uma espacialização heterogênea, sendo verificadas manchas das cinco classificações estabelecidas. No entanto, as porções majoritárias são as ruins. Tal acontecimento pode ser explicado pelas grande áreas sujeitas a alagamento, e também, pela presença de habitações com saneamento básico abaixo do esperado. Já as áreas com IDQS satisfatório e bom correspondem às áreas verdes e domicílios com renda salarial considerávele acesso à condição sanitária de qualidade.

Por fim, a região Leste da capital mineira possui um contraste entre áreas satisfatórias e ruins de tamanho relevante. Acredita-se que as primeiras ocorrem devido à presença de setores censitários com relativa predominância de focos verdes. Contudo, as porções ruins correspondem às áreas com população de baixa renda e saneamento precário.

Em suma, o que se pode concluir da espacialização do IDQS é que não foram encontradas manchas totalmente uniformes em grande escala no município de Belo Horizonte. Isso significa que o Índice proposto também pode detectar especificidades.

Acredita-se que esta característica deve-se ao fato de que os dados foram manipulados em nível de setores censitários, a mínima unidade de análise socioeconômica, além das 
variáveis de resposta espectral, as quais advém de uma resolução espacial de 20 metros. Nesse ínterim, os procedimentos de correção geométrica e ajustes adotados deram um ganho considerável nomanuseio das imagens de satélite, compreendendo as etapas de préprocessamento, realce e classificação. De maneira oportuna, vale ressaltar a disponibilidade das cenas CBERS numa temporalidade satisfatória para análise, além do baixo percentual de recobrimento por nuvens.Destarte, foram dispensados no tratamento inicial quaisquer tipos de correção de natureza atmosférica. Os posteriores resultados de classificação e procedimentos avançados de geoprocessamento trouxeram respostas satisfatórias e permitiram avaliar positivamente os procedimentos adotados.

Ainda assim, vê-se a possibilidade de incrementar a análise com outras variáveis, abrindo possibilidades de caracterizar não só a condição do saneamento ambiental, como também dar um passo à frente para a avaliação da qualidade ambiental urbana. Outros trabalhos científicos já obtiveram respostas satisfatórias nesse quesito, entretanto, dá-se a importância de adequar e utilizar técnicas variadas e quantitativas como a adotada neste trabalho.

A criação de indicadores pode contribuir com as políticas públicas, principalmente nos grandes centros urbanos, onde a velocidade de transformação do espaço - sequente urbanização - preocupa as autoridades e sociedade.

A caracterização espacial dos IDQS revelou uma aproximação da realidade da capital mineira. Isso remonta a ideia de que o Índice aqui proposto pode ter um alcance de resposta justificado e de grande capacidade. Outras inúmeras colocações e discordâncias poderiam serestabelecidas, de modo que somente o desenvolvimento mais apurado das técnicas aqui definidas e o debate entre sociedade e poder público, levantaria hipóteses de aplicação para uma melhor caracterização do saneamento ambiental em Belo Horizonte. Enfim, acreditaseque os resultados aqui encontrados possam contribuir para a difusão das técnicas e a elaboração de políticas públicas sustentáveis capazes de avaliar e prever as condições da população residente urbana. 


\section{REFERÊNCIAS BIBLIOGRÁFICAS}

BARROS, R. T. V. et allii. Manual de Saneamento e proteção ambiental para os municípios. Volume 2: Saneamento. Belo Horizonte. Escola de Engenharia da UFMG, 221 p. 1995.

BONDUKI, N. G. (org.). Hábitat: as práticas bem-sucedidas em habitação, meio ambiente e gestão urbana nas cidades brasileiras. $2^{a}$ ed. São Paulo: Studio Nobel, 268 p. 2003.

BORJA, P. C. Metodologia para a avaliação da qualidade ambiental urbana em nível local. 2003.

BRASIL, Lei $\mathrm{n}^{\circ}$ 11.445, de 5 de Janeiro de 2007. Estabelece diretrizes nacionais para o Saneamento

Básico; altera as Leis nos 6.766, de 19 de dezembro de 1979, 8.036, de 11 de maio de 1990, 8.666, de21 de junho de 1993, 8.987, de 13 de fevereiro de 1995; revoga a Lei no 6.528, de 11 de maio de1978; e dá outras providências.

BRASIL, Ministério das Cidades. Cadernos Ministério das Cidades Saneamento Ambiental. Volume5: Saneamento ambiental. Governo Federal, 2005, pág. 49.

CIDADE, L. C. A questão ambiental urbana: perspectivas de análise. In: Encontro Nacionalda ANPUR, Brasília, 1995. Anais ... Brasília: ANPUR, 1996.

FERREIRA, M. R. P. Análise discriminante clássica e de núcleo: avaliações a algumas contribuiçõesrelativas aos métodos boosting e bootstrap. Dissertação de Mestrado. Instituto de Ciências Exatas.Departamento de Estatística. UFPE. 2007.

FERGUSON, J. Introduction to linear algebra in geology. Chapman \& Hall, London - UK, 1994.

LIMA, V.; AMORIM, M. C. Metodologia para analisar a Qualidade Ambiental Urbana através de

Geoprocessamento. 2002.

LIMA, V. Análise da qualidade ambiental urbana de Osvaldo Cruz/SP. Dissertação de Mestrado.

Universidade Estadual Paulista, Presidente Prudente/SP, 2007.

LUENGO, G. Elementos para ladefinición y evaluación de lacalidad ambiental urbana. Uma propuesta teórico-metodológica. Anais do IV Seminário Latinoamericano de Calidad de VidaUrbana. Tandil(Argentina), 8 a 11 de setembro de 1998.

MORETT, A. J. Um estudo para ajuste na metodologia de gerenciamento de processoinserindo os fatores legal, social e ambiental em sua análise. 2002. 283f. Tese (Mestrado em Engenharia de Produção) - Universidade Federal de Santa Catarina, Florianópolis, 2002.

OKANO, N.H. et al. Saneamento Ambiental. Série de Cadernos Técnicos da Agenda Parlamentar.

CREA-PR. 2009. 
OPAS. Organização Pan-Americana da Saúde nas Américas: 2007 Washington, D.C.: OPAS, C

2007. 2

v. (OPAS, Publicação Científica e Técnica,

n.

622). Disponível em:http://www.opas.org.br/publicmo.cfm?codigo=97. Acessoem 15 de Novembro. 2010.

WILL, J. e BRIGGS, D. Developing Indicators for Environment and Health. Word Health Statistics Quarterly. Rapport. Trimentriel de StatistiquesSanitairesMondiales. Genève, v. 48, $\mathrm{n}^{\circ}$ 2, p.155 - 163, 1995. 